\title{
Percutaneous Closure of Paravalvular Leaks: A Systematic Review
}

\author{
IGNACIO CRUZ-GONZALEZ, M.D., Ph.D., ${ }^{1 *}$ JUAN C. RAMA-MERCHAN, M.D., Ph.D., ${ }^{1 *}$ \\ PATRICK A. CALVERT, M.D., Ph.D., ${ }^{2}$ JAVIER RODRÍGUEZ-COLLADO, M.D., ${ }^{1}$ \\ MANUEL BARREIRO-PÉREZ, M.D. Ph.D., ${ }^{1}$ JAVIER MARTÍN-MOREIRAS, M.D., Ph.D., ${ }^{1}$ \\ ALEJANDRO DIEGO-NIETO, M.D., Ph.D., ${ }^{1}$ DAVID HILDICK-SMITH, M.D., ${ }^{3}$ \\ and PEDRO L. SÁNCHEZ, M.D., Ph.D. ${ }^{1}$ \\ From the ${ }^{1}$ University Hospital of Salamanca, IBSAL, Salamanca, Spain; ${ }^{2}$ Queen Elizabeth Hospital, University Hospitals Birmingham and \\ Institute of Translational Medicine, University of Birmingham, United Kingdom; and ${ }^{3}$ Sussex Cardiac Centre, Brighton and Sussex \\ University Hospitals, United Kingdom
}

\begin{abstract}
Paravalvular leak (PVL) is an uncommon yet serious complication associated with the implantation of mechanical or bioprosthetic surgical valves and more recently recognized with transcatheter aortic valves implantation (TAVI). A significant number of patients will present with symptoms of congestive heart failure or haemolytic anaemia due to PVL and need further surgical or percutaneous treatment. Until recently, surgery has been the only available therapy for the treatment of clinically significant PVLs despite the significant morbidity and mortality associated with re-operation. Percutaneous treatment of PVLs has emerged as a safe and less invasive alternative, with low complication rates and high technical and clinical success rates. However, it is a complex procedure, which needs to be performed by an experienced team of interventional cardiologists and echocardiographers. This review discusses the current understanding of PVLs, including the utility of imaging techniques in PVL diagnosis and treatment, and the principles, outcomes and complications of transcatheter therapy of PVLs. (J Interven Cardiol 2016;29:382-392)
\end{abstract}

\section{Introduction}

Paravalvular leak (PVL) is an uncommon yet serious complications associated with the implantation of mechanical or bioprosthetic surgical valves and more recently recognized with transcatheter aortic valves implantation (TAVI). ${ }^{1,2}$

PVLs with trivial or mild regurgitation are present at hospital discharge in up to $17.6 \%$ and $22.6 \%$ of

\footnotetext{
*Ignacio Cruz-Gonzalez and Juan C. Rama-Merchan have contributed equally and are co-first authors.

Conflicts of interest: Dr. Cruz-Gonzalez is proctor for St. Jude Medical. Dr. Hildick-Smith is proctor or Advisory for St. Jude, Gore, Occlutech. Dr. Calvert is proctor for St. Jude Medical. Authorship declaration: All authors listed meet the authorship criteria according to the latest guidelines of the International Committee of Medical Journal Editors. All authors are in agreement with the manuscript.

Address for reprints: Juan C. Rama-Merchan, M.D., Ph.D., Department of Cardiology, University Hospital of Salamanca, Paseo de San Vicente 58-187, 37007 Salamanca, Spain. Fax: 34-923270008; e-mail: ramamerchan@hotmail.com
}

surgical aortic and mitral valve replacement, respectively. ${ }^{3}$ Identified risk factors for PVL after surgical valve replacement include extensive calcification of the annulus, presence of endocarditis, large atria, renal insufficiency and older age. ${ }^{4}$ In patients undergoing TAVI, risk factors include annular calcification and incorrect pre-procedural valve sizing. ${ }^{2,5}$ With mild or moderate PVLs, patients are usually asymptomatic. ${ }^{6}$ However, patients with severe PVLs often have symptoms of heart failure (HF) or haemolytic anaemia (HA) and should be treated invasively. ${ }^{6}$ Probably in patients with moderate PVLs and refractory HF or HA might also be reasonable to close the PVL. Clinically significant PVLs that warrant repair occur in $1-4 \%$ of patients with prosthetic valves. ${ }^{7}$

Until recently, surgery has been the only available therapy for the treatment of clinically significant PVLs. However, re-operation is associated with significant morbidity and mortality. ${ }^{8}$ They have been reported hospital mortality rates of $12.6 \%, 14.9 \%$ and $37 \%$ after the first, second and third or subsequent re- 
operation, respectively. ${ }^{8}$ Furthermore, PVL recurrence after first redo surgery has been reported to be $13 \%$ and increases further to $35 \%$ after second redo surgery. ${ }^{9}$

Percutaneous treatment of PVLs has emerged in the last few years as a safe, effective and less invasive alternative to surgery. ${ }^{10-13}$ Percutaneous repair cannot be performed or is contraindicated in patients with active endocarditis, significant dehiscence involving more than one-third of the valve ring or if the prosthesis is "rocking".

\section{Imaging in Transcatheter Paravalvular Leak Closure}

Transesophageal echocardiography (TEE) is the gold standard technique to establish the PVL diagnosis and to assess the degree of paravalvular regurgitation (PVR), ${ }^{14,15}$ (Fig. 1). Two-dimensional (2D)-TEE is very sensitive in accurately identifying the presence of PVL (88\%). ${ }^{16}$ However, to assess the number, extent, shape and exact anatomical location of the PVL can be very challenging. ${ }^{17}$ Several studies have demonstrated the concordance between 3D-TEE images and the real anatomy, and the superiority of 3D-TEE over 2D-TEE in PVL evaluation. ${ }^{18-20}$ To facilitate the communication between the interventionalist and echocardiographer, it is recommended that mitral PVL location be reported in a clockwise format from a surgeon's perspective or 'surgical view' (Fig. 2). ${ }^{14,15}$ To determine the aortic PVL position, is also recommended to use the clockwise format. The non-coronary cusp is between 7 o'clock and 11 o'clock, the left coronary cusp is between 11 o'clock and 3 o'clock, and the right coronary cusp is between 3 o'clock and 7 o'clock (Fig. 2). ${ }^{10}$

Assess the severity of the PVL is complex and multiple 2D and 3D-TEE parameters (qualitative and

Figure 1. Echocardiographic evaluation of a mitral PVL. A: 3D-TEE imaging of a prosthestic mitral valve in the surgical position with asterisks identifying two PVLs. B: 3D-TEE colour doppler imaging of the same patient with arrows identifying two jets of mitral PVR (11:00 h and 2:00 h). C: Sizing of a mitral PVL by 3D-TEE using the QLAB software (Philips Medical). D: 3D-TEE imaging during the transseptal puncture. 'Tenting' of the atrial septum can be seen (red asterisk). E: Guidewire across the mitral PVL (red asterisk). F: AVP-III devices deployed (red asterisk). LAA, left atrial appendage; Ao, Aortic valve. RA, right atrium; LA, left atrium.

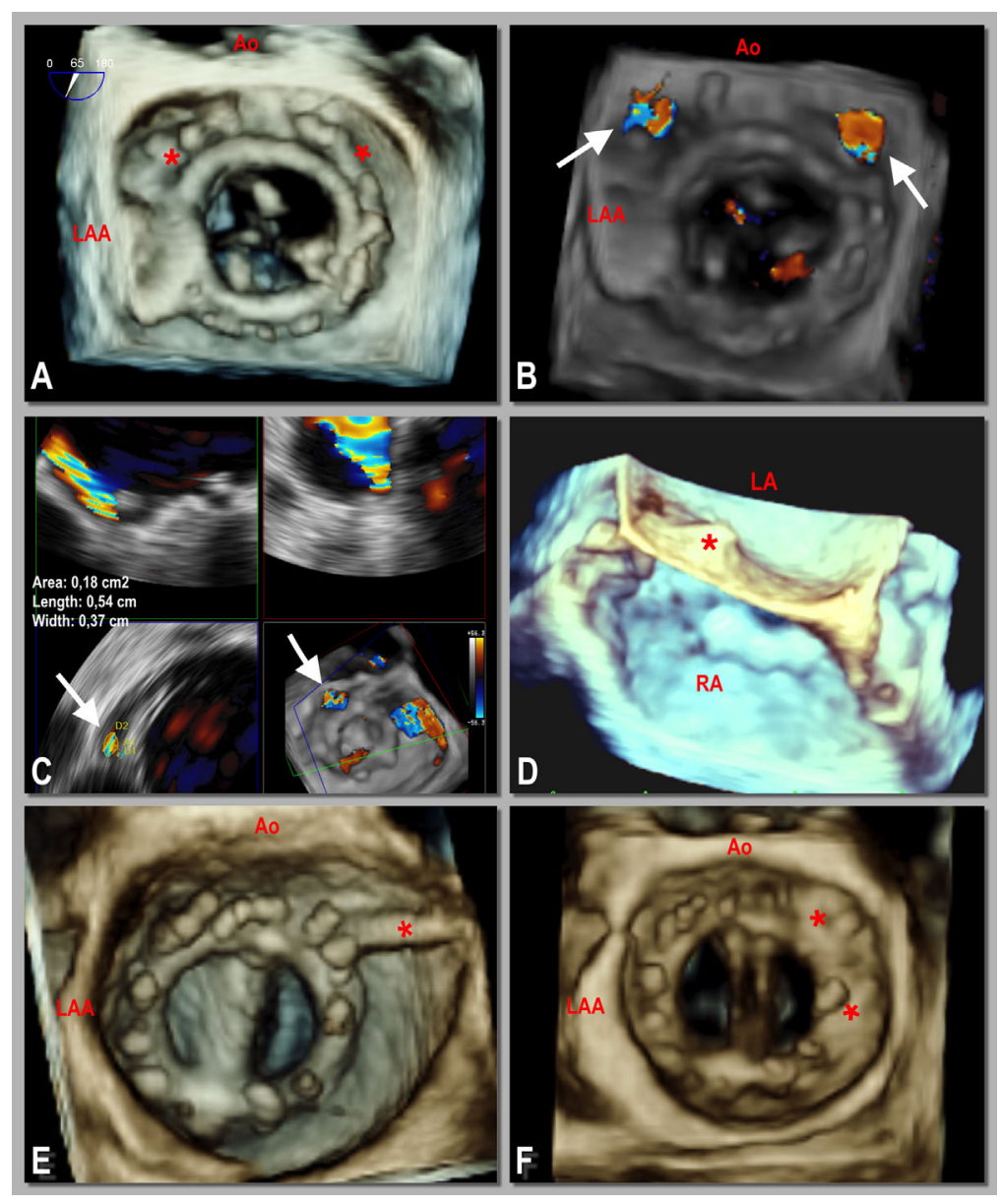




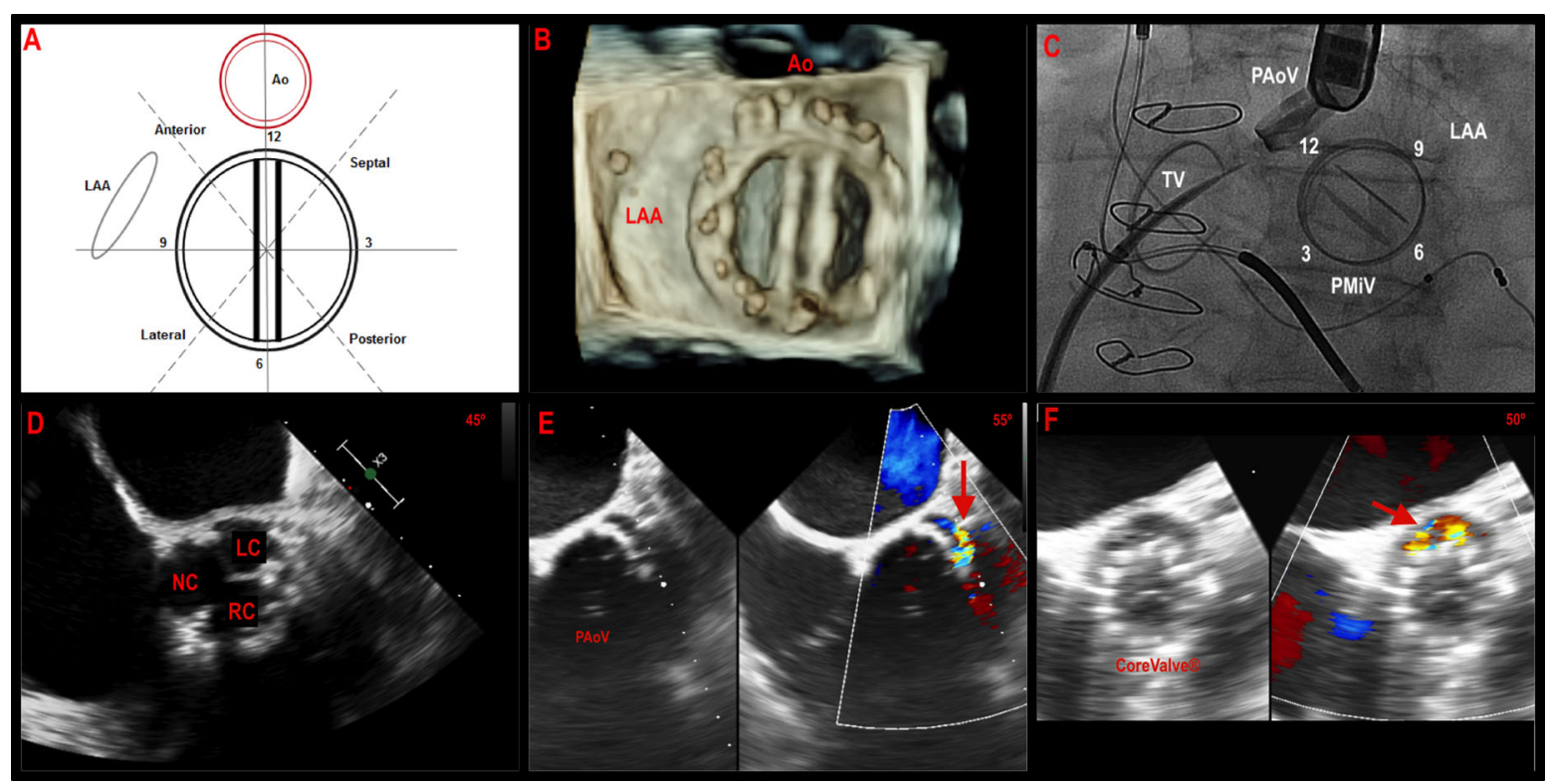

Figure 2. Mitral and aortic PVLs location. A: Schematic view of the mitral valve as seen from the left atrial perspective, oriented in the surgical view. The aortic valve is positioned at 12 o'clock, the LAA is a 9 o'clock. The interatrial septum is located at 3 o'clock, and the posterior mitral annulus is at 6 o'clock. B: 3D-TEE imaging, face view of the prosthetic mitral valve in a "surgical view" orientation. C: Fluoroscopic left caudal view ("spider" angiographic view) showing mechanical mitral and aortic prostheses. The surgeon's-view time-clock method is shown: 12:00 is in the upper position and 3:00, on the septal side, whereas 9:00 is on the LAA side. D: 2D-TEE midesophageal aortic valve short axis view. E: Aortic PVL in the left coronary sinus region (red arrow). F: 2D-TEE imaging showing a crescent-shaped aortic PVL after CoreValve ${ }^{\circledR}$ implantation in posterior region (red arrow). LAA, left atrial appendage; Ao, Aortic valve. PMiV, prosthetic mitral valve; PAoV, prosthetic aortic valve. NC, non-coronary cusp; LC, left coronary cusp; RC, right coronary cusp; TV, tricuspid valve.

quantitative) are often required. ${ }^{14,15}$ Also, 3D-TEE is the recommended technique to guide percutaneous PVL closure procedures (Fig. 1)..$^{14,15,21}$ Note that although 3D-TEE is an essential tool in the percutaneous closure of mitral PVLs, it can be not as necessary in the closure of aortic PVLs. In addition, in certain cases, intracardiac echocardiography can be an alternative or a complementary technique to TEE. ${ }^{22}$ 3D-TEE also plays an important role in the selection of the most appropriate closure device (morphology and size) in each case. ${ }^{20,23}$ For this purpose it is essential to perform a thorough characterization of the PVL (length, width, area) by direct planimetry using a 3D multiplanar reconstruction tool. ${ }^{20}$

Fusion of different imaging modalities has gained increasing popularity over the last years. ${ }^{24}$ Computed tomography (CT)-fluoroscopy fusion imaging represents a new option especially useful in trasapical access. ${ }^{24}$ However, to date there is only limited evidence that fusion imaging improves safety and outcomes in these procedures. ${ }^{25}$

\section{Transcatheter Paravalvular Leak Closure Techniques}

PVL closure is usually performed under general anesthesia, with 2D/3D-TEE and fluoroscopic guidance.

Mitral PVL Closures. Mitral PVL closure, compared with aortic PVL closure, is technically more challenging. Approaches include transfemoral antegrade and retrograde, and transapical (Fig. 3).

The antegrade approach is performed via a transseptal puncture. After obtaining transseptal access using standard techniques, heparin is administered. It is usually recommended to perform a low puncture for septal PVLs, and a relatively high puncture for lateral and posterior PVLs. Subsequently, a diagnostic catheter, such as a multipurpose or Judkins right (JR), is advanced into the left atrium (LA). A $0.035^{\prime \prime}$ hydrophilic guidewire (e.g., Terumo guidewire, Terumo Medical-Corporation) is generally used to cross the PVL, and the catheter is advanced over the wire 


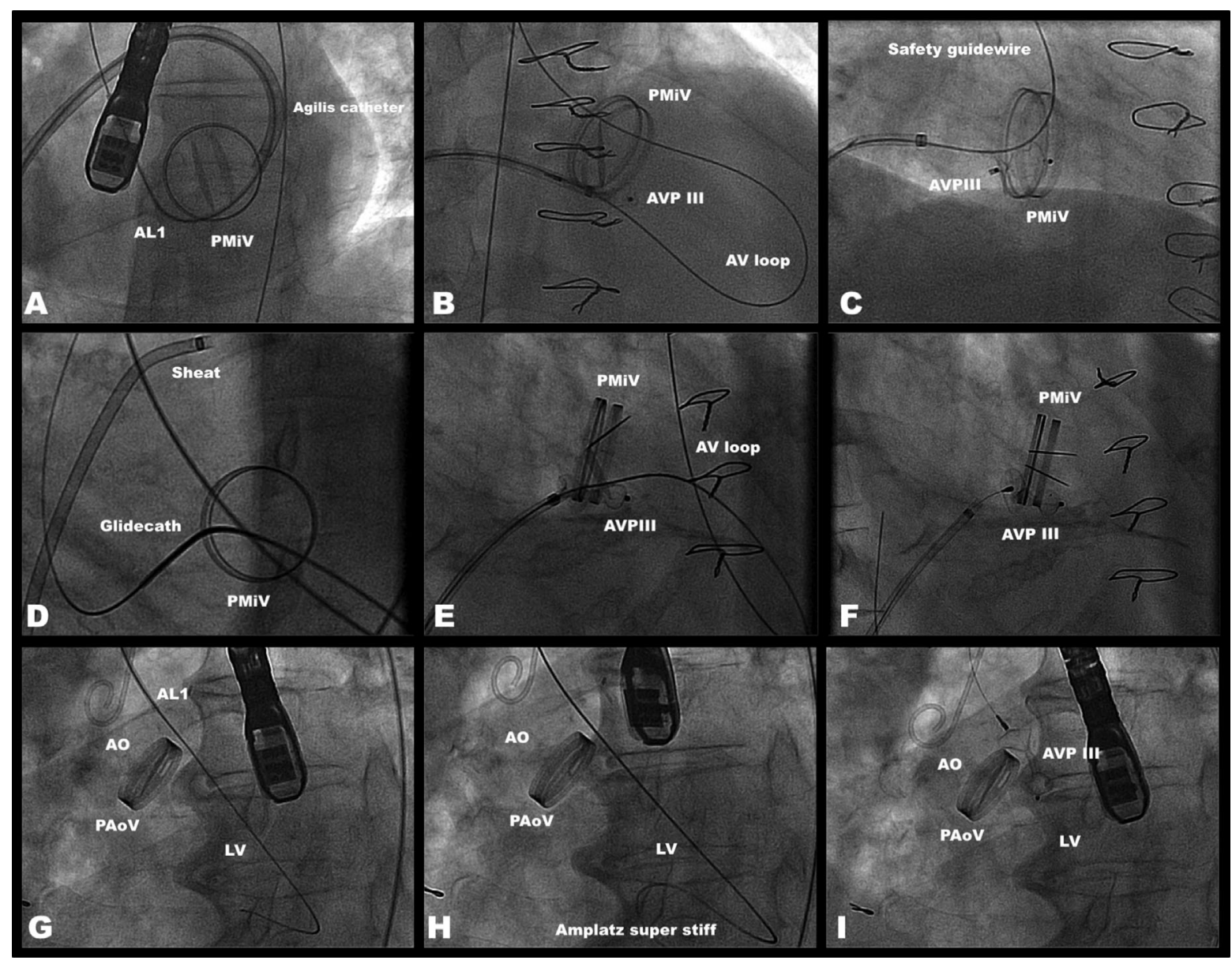

Figure 3. Techniques for PVL closure. A-C: Antegrade Transseptal Approach for mitral PVL closure. D-F: Retrograde aortic approach for mitral PVL closure. G-I: Retrograde aortic approach for aortic PVL closure. PAoV, prosthetic aortic valve; PMiV, prosthetic mitral valve; AO, Aorta; AL, Amplatzer left; AV, arteriovenous; LV, left ventricle; AVP, Amplatzer Vascular Plug.

into the left ventricle (LV) (Fig. 3). After that, in most cases an arteriovenous (AV) loop is established snaring the wire in the aorta, or the guidewire is exchanged for a high-support wire (Fig. 3). Finally, a delivery sheath is advanced over the loop across the PVL and the closure device is deployed. With a sheath at least one French size bigger than the recommended size for a specific device deployment, we can keep the wire/AV loop in place and it can be used as a "safety" wire. This "safety" wire allows repeat advancement of the delivery sheath in case there is need for repeat deployment. A mitral PVL in a septal location can sometimes be very challenging due to the significant angulation required to cross the defect. In these cases, it can be very helpful to use a telescopic catheter system $^{26}$ or a deflectable catheter (Agilis, St. JudeMedical) (Fig. 3). ${ }^{12}$

In the retrograde approach, a $0.035^{\prime \prime}$ hydrophilic guidewire over a catheter (e.g., JR or Amplatz left (AL) catheter) is often used to cross the PVL from the LV to the LA. After that, an AV wire loop is created snaring the wire in the LA and the delivery sheath is advanced over the loop from the venous access (Fig. 3).

After apical access, a hydrophilic guidewire is often used supported by a steerable catheter to direct the wire towards the PVL. Once across the defect, the wire is exchanged for a high-support wire. Then, the delivery sheath is advanced across the PVL and the device is deployed into the defect. This 
technique can be performed percutaneously or with a minithoracotomy. ${ }^{10}$

Paravalvular Mitral Leak Closure With Multiple Devices. If pre-procedural or intra-procedural imaging suggests that the PVL cannot be completely closed with a single device, multiple devices can be deployed simultaneously or sequentially with the following techniques. To deploy two devices simultaneously, once the PVL has been crossed and the AV loop established, the delivery sheath is advanced through the PVL. Subsequently, another guidewire is inserted by the delivery sheath and a second AV loop is established. After removing the delivery sheath, two delivery sheaths are advanced (one on each wire). Finally, two devices are deployed simultaneously (Fig. 4). Another approach is to deploy a first device without releasing it from the delivery cable, remove the delivery sheath and advance it again over the "safety" guidewire. Then a second device is advanced and deployed, and both are released (Fig. 4). Finally, another approach is to deploy both devices using the same delivery sheath one after the other. In this case, the first device is deployed and released. After that, the delivery sheath is advanced again over the safety guidewire and the second device is advanced and deployed. This technique has the great disadvantage that the first device can migrate at the time of deploying the second device. Furthermore, if we do not have a safety wire, it is necessary to cross the PVL again (Fig. 4).

In our opinion, the deployment of multiple smaller devices rather than 1 or 2 larger devices has a better

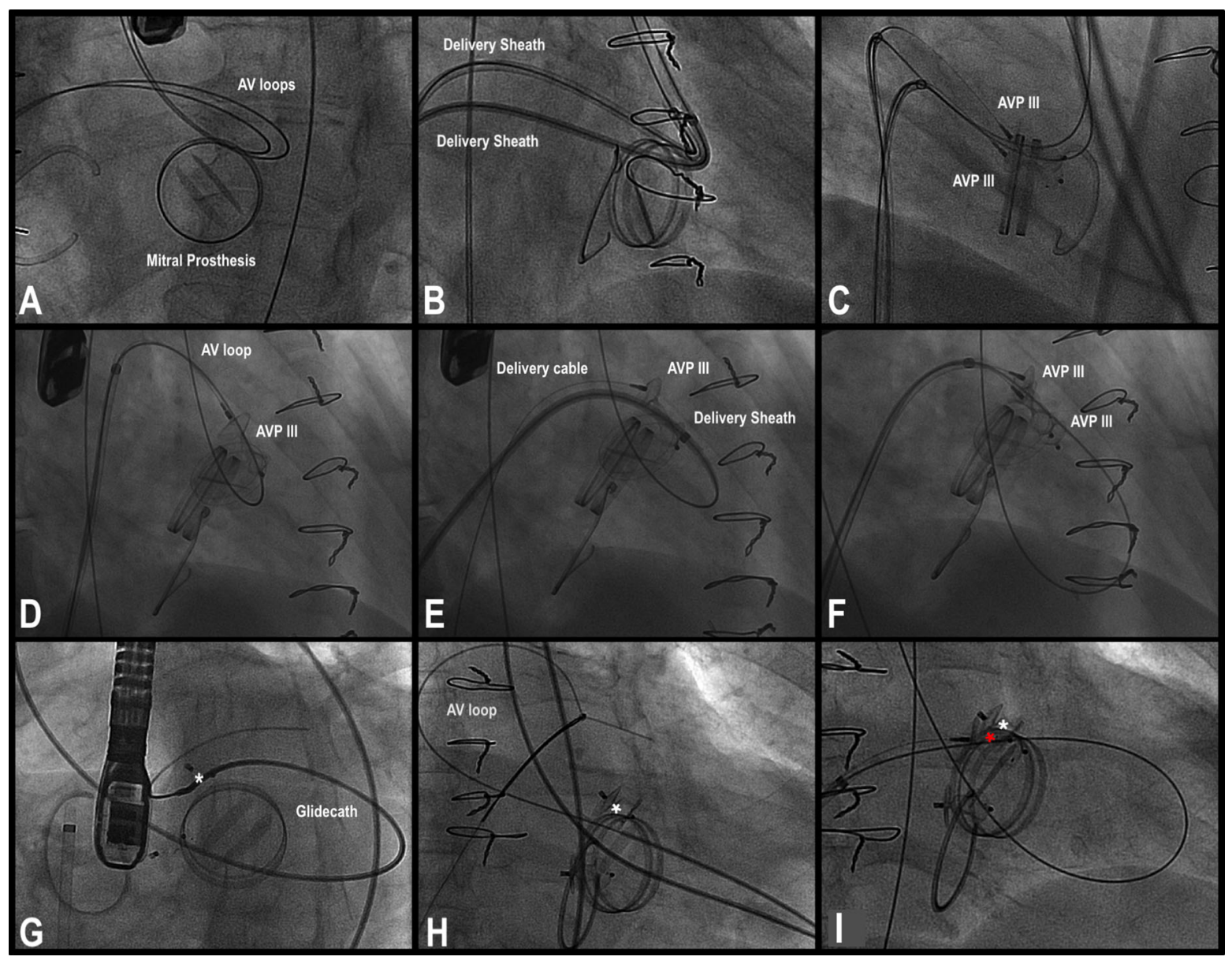

Figure 4. Mitral PVL closure with multiple devices. A-C: Deployment of two devices simultaneously. D-F: Deployment of two devices sequentially. G-I: Deployment of two devices (asterisks) using the same delivery sheath one after the other (noting that after deploying the first device, the PVL is crossed again). AV, arteriovenous; AVP, Amplatzer Vascular Plug. 
sealing within the PVL and less interference with the prosthesis discs. Moreover, the adaptation of the devices to the anatomy of the defect is probably greater when both devices are deployed simultaneously.

Paravalvular Mitral Leak Closure in Special Situations. Occasionally the closure of a PVL can be very challenging. If the bioprosthetic surgical valve is radiolucent throughout, the procedure becomes fluoroscopically complex. ${ }^{27}$ In this case, 3D-TEE is critical during the procedure. Another complex situation is the closure of PVL in patients with mitral and aortic mechanical valve prosthesis. Mechanical aortic prostheses have been considered an important limitation or contraindication for percutaneous closure of mitral PVLs using femoral access with a retrograde approach. In this sense, we have recently reported ${ }^{28}$ the retrograde approach of mitral PVLs using a hydrophilic catheter to cross the aortic prosthesis and establish an AV loop. Alternatively the procedure may be done using a pre-shaped super-support wire in the left ventricle via the transseptal puncture, therefore, avoiding the need for an AV loop.
Another challenging situation is the closure of mitral PVL in patients with percutaneous valve-inring implantation. We have also recently reported the first-in-man percutaneous transseptal closure of paravalvular regurgitation after valve-in-ring (Edwards SAPIEN XT valve, Edwards Lifesciences) implantation. ${ }^{29}$

Aortic PVLs Closure. In patients with an aortic PVL, the retrograde femoral arterial approach is most commonly used (Fig. 3). The PVL is usually crossed using a $0.035^{\prime \prime}$ hydrophilic guidewire via a catheter (e.g., AL-1). Once the PVL is crossed, the wire is routinely exchange for a stiffer wire (e.g., Amplatz Super-stiff ${ }^{\mathrm{TM}}$, Boston Scientific) to provide support (Fig. 3). The delivery sheath is then advanced over the guidewire and the device of choice is deployed in the PVL. In some cases where an extra support is needed, an arterio-arterial loop can be established. For that, once the PVL has been crossed, the guidewire is directed towards the aorta (through the aortic valve). Finally the guidewire is captured in descending aorta and "exteriorized" via the left femoral artery. Another
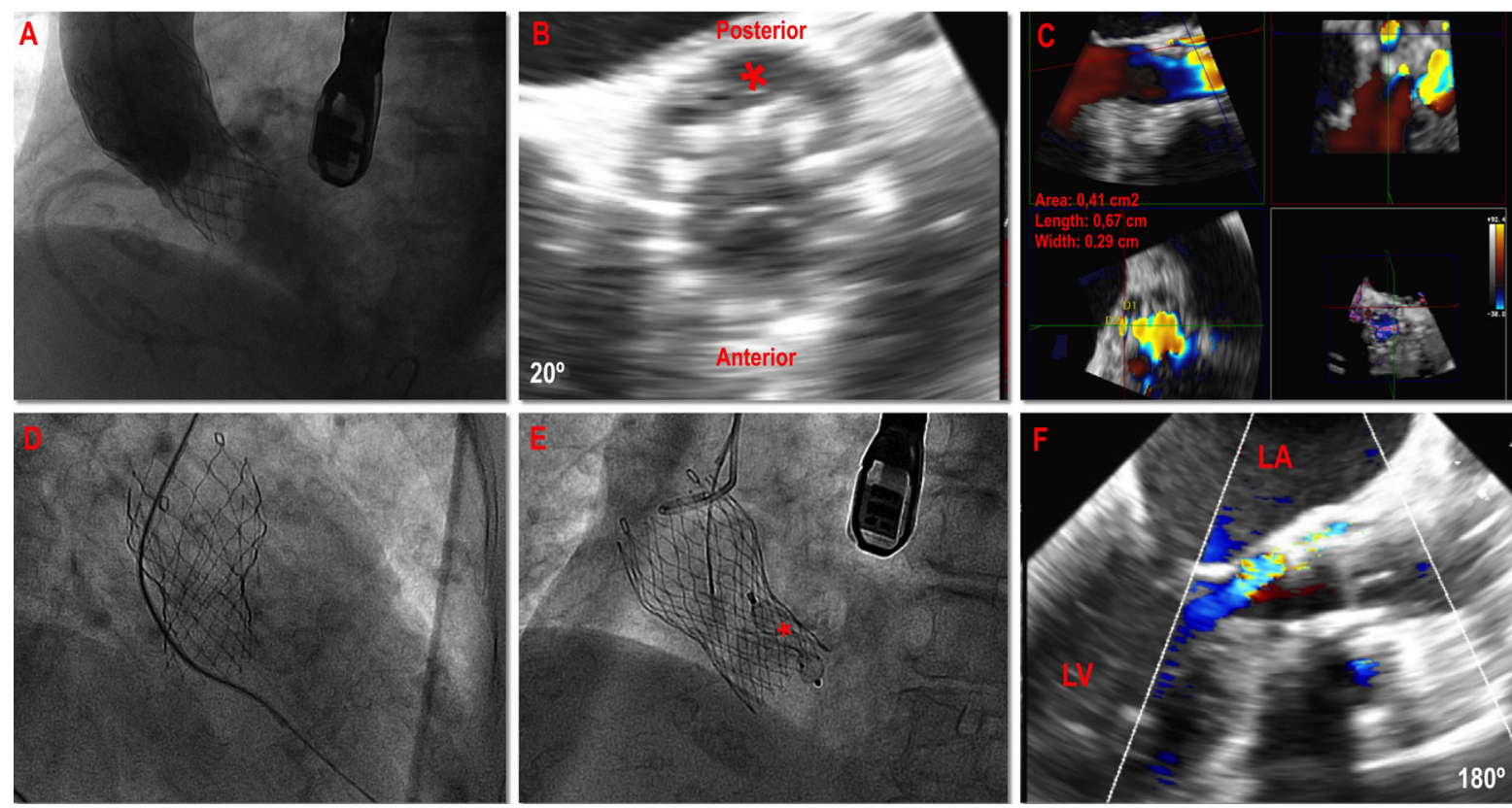

Figure 5. Percutaneous PVL closure after TAVI. A: Significant PAR due to major focal calcification after implantation of a CoreValve ${ }^{\circledR}$ valve. B: $20^{\circ}$ (Short axis) TEE showing the PVL (red arterisk). C: Measurements of the length, width, and area of the PVL were performed by 3D-TEE planimetry using the QLAB multiplanar reconstruction tool (Philips Medical). D: A 5-F Amplatz-Left-1 catheter and straight hydrophilic guide wire crossing the PVL. E: Deployment of the $8 \mathrm{~mm}$ AVP IV device (red asterisk). F: $180^{\circ}$ TEE showing marked reduction of the PAR. LA, left atrium; LV, left ventricle. 
option could be the use of a combined retrograde/ antegrade approach. ${ }^{30}$

\section{Paravalvular Leak After Transcatheter Aortic Valve Replacement}

Paravalvular aortic regurgitation (PAR) after TAVI is not uncommon. Depending on the method of assessment, the reported prevalence of this complication varies from $40 \%$ to $67 \%{ }^{31,32}$ for trivial to mild PVLs and from $7 \%$ to $20 \%{ }^{31-33}$ for moderate to severe PVLs. A recent meta-analysis including 12.926 TAVI patients reported a pooled estimate incidence of moderate or severe PAR of $11.7 \% .^{34}$

Assess the severity of the PAR after TAVI is difficult on many occasions and it is often necessary to use several imaging techniques. ${ }^{35}$ PAR most commonly results from: $:^{2,5}$ (1) incomplete prosthesis apposition to the native annulus due to extent of calcification or annular eccentricity, (2) prosthesis under-sizing and/or (3) prosthesis malpositioning (high or low implantation), (Fig. 5). In most cases, PAR is mild and clinically silent. ${ }^{36}$ However, residual moderate/severe PAR has a relevant negative prognostic impact and has been associated with an increased risk of all-cause mortality. ${ }^{34,37}$

Saia et al. ${ }^{2}$ have recently published the largest series of percutaneous PVL closure after TAVI. They included 24 patients (13 with Edwards-Sapien ${ }^{\circledR}$ valve and 11 with CoreValve ${ }^{\circledR}$ valve). The success of the procedure was $88.9 \%$ (in the first procedure) and $91.7 \%$ (after performing more than one procedure in 2 patients). A significant improvement of the functional status of the patients after the procedure was observed.

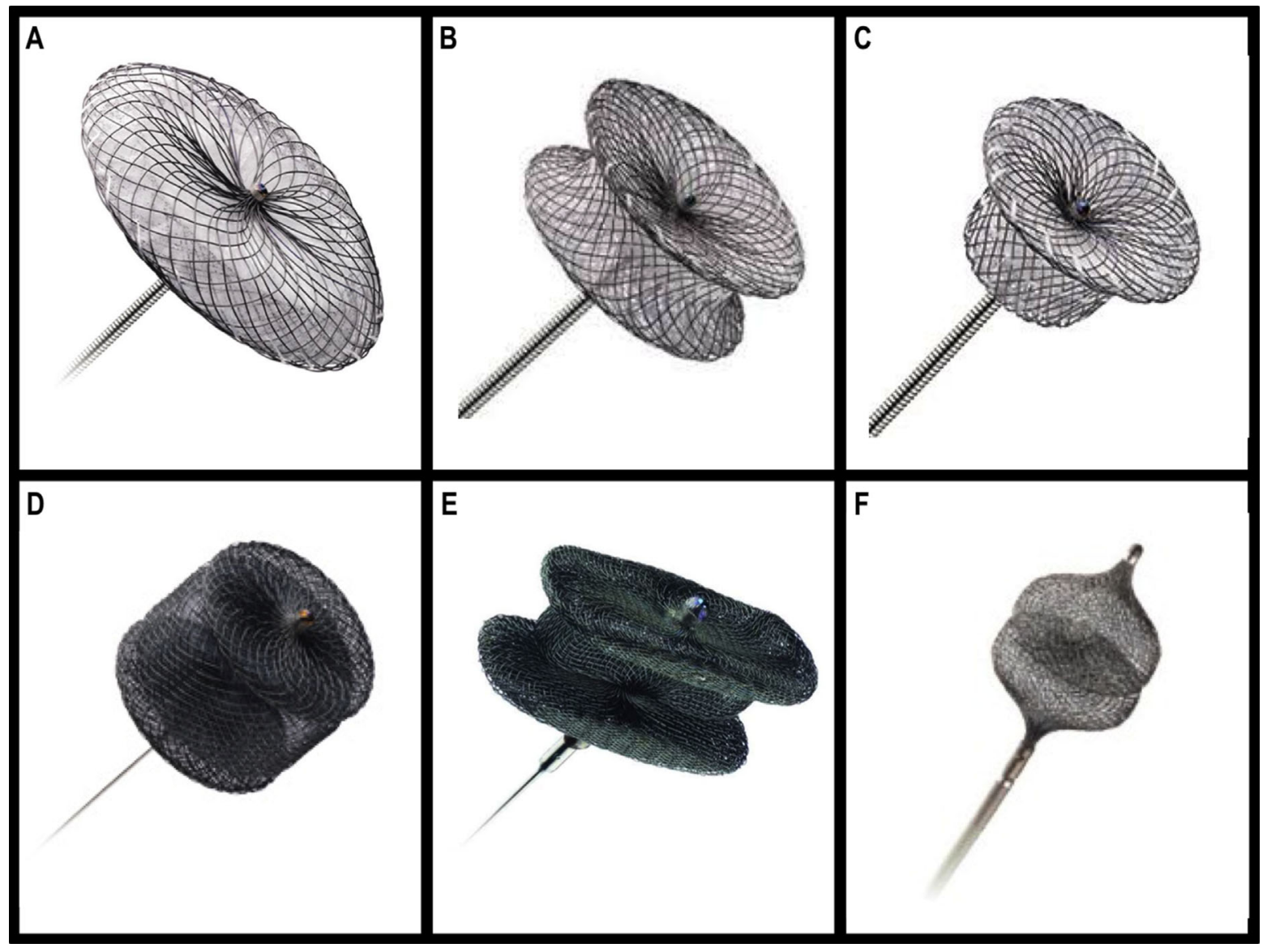

Figure 6. Family of Amplatzer devices (St Jude Medical). A: Amplatzer Septal Occluder. B: Amplatzer Muscular VSD Occluder. C: Amplatzer Duct Occluder. D: Amplatzer Vascular Plug II. E: Amplatzer Vascular Plug III. F: Amplatzer Vascular Plug IV. 
PERCUTANEOUS CLOSURE OF PVL

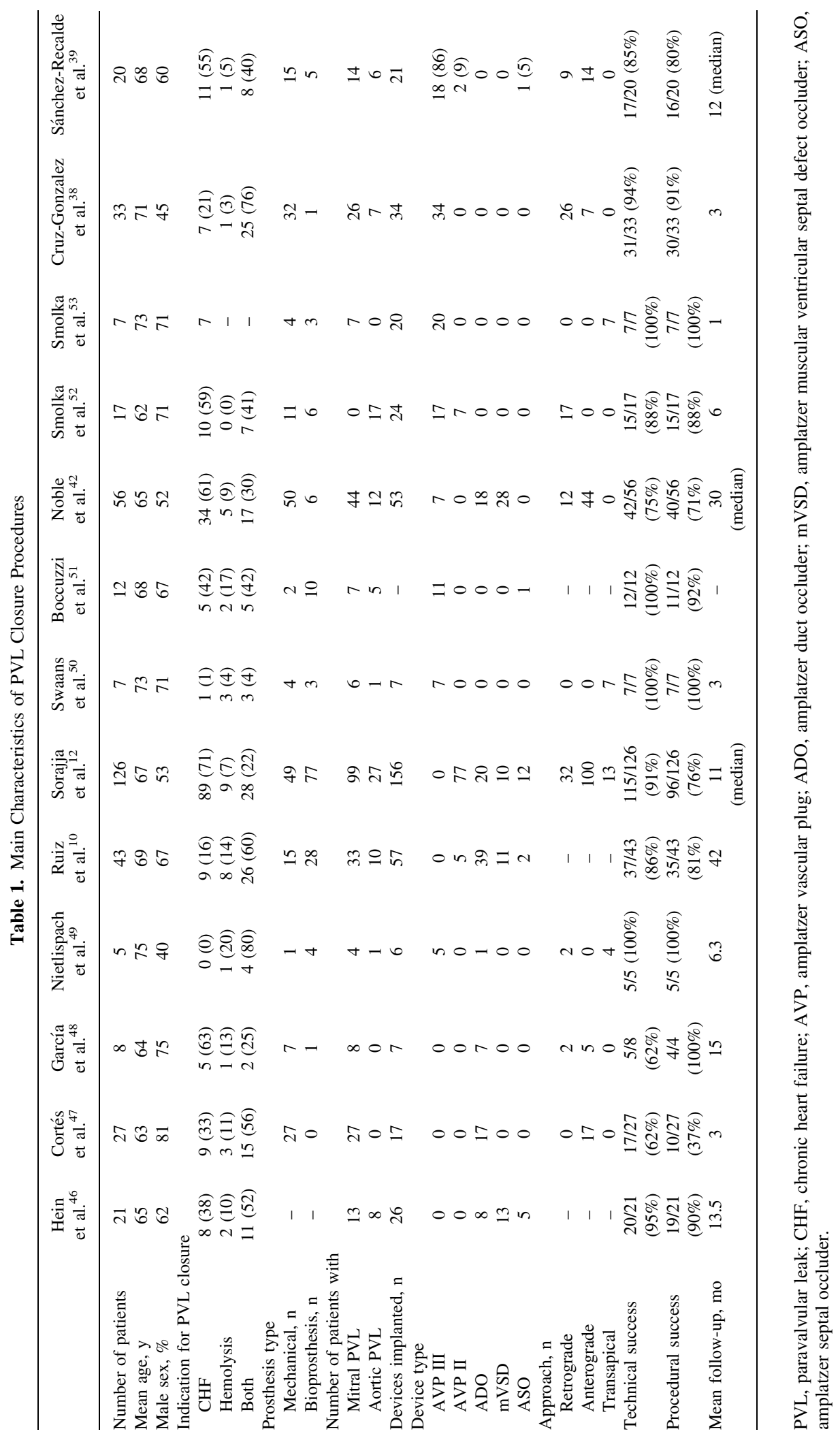




\section{Paravalvular Leak Closure Devices}

Currently, the devices most commonly used (off-label) to PVL closure are the Amplatzer family of devices (St. Jude Medical) (Fig. 6). The Amplatzer Vascular Plug (AVP) II is the most used device in the United States. Outside of the United States, the most used device is the AVP III. ${ }^{38-40}$ It has European Commission approval to embolize blood vessels in the peripheral vasculature, but has not received Food and Drug Administration approval in the United States. Recently, the Occlutech device (Helsingborg, Sweden) has been the first to obtained European Commission approval for PVL closure. ${ }^{41}$

\section{Outcomes and Complications of Percutaneous Paravalvular Leak Closure}

The safety and feasibility of percutaneous PVL closure procedures have been confirmed in several studies, registries and a meta-analysis, ${ }^{10,11,13,38,42}$ (Table 1). Reported technical success (defined as the correct deployment of an occlusive device through the PVL and the lack of significant residual regurgitation or new prosthetic valve malfunction) ranged from $77 \%$ to $86 \%$. Likewise, reported clinical success (defined as a reduction of $\geq 1$ grade on the New York Heart Association functional class scale and/or improvement in HA) ranged from $67 \%$ to $77 \%$. Procedural failures were attributed mainly to an inability to cross the defect or interference of the device with prosthetic valve function.

In a meta-analysis recently published by Millán et al., ${ }^{13}$ a successful PVL reduction was associated with a lower cardiac mortality rate compared with a failed reduction (260 patients; OR, 0.08; 95\% CI 0.01-0.90). A positive tendency toward lower all-cause mortality was also observed in successful procedures (311 patients; OR, 0.52; 95\% CI, 0.09-1.74). Also, a superior functional class improvement or improved HA was observed in successful compared with failed PVL reductions (267 patients; OR, 9.95; 95\% CI, 2.10-66.73). Procedurally successful transcatheter PVL reduction was also associated with fewer surgical reinterventions (316 patients; OR, 0.08; 95\% CI, 0.01-0.40).

However, there are several complications that can occur either during percutaneous PVL closure or in follow-up, ${ }^{10,11}$ (Table 2). The main in-hospital complications related to the surgical correction of
Table 2. Main Complications Associated With PVL Closure

\begin{tabular}{lc}
\hline Complications & Percentage \\
\hline Percutaneous closure & \\
$\quad$ Emergency cardiac surgery for & $0.9 \%(12)$ \\
$\quad$ prosthetic impingement & \\
Device embolization & $4 \%(10)$ \\
Embolic stroke & $1.7 \%(12)$ \\
Intracranial hemorrhage & $0.9 \%(12)$ \\
Cardiac perforation & $4 \% *(10), 0 \%(38)$, \\
& $0 \%(12)$ \\
Vascular complications & $2 \%(10), 0.9 \%(12)$ \\
Sepsis & $0.9 \%(12)$ \\
Death & $2 \%(10), 1.7 \%(12)$ \\
Surgical correction & \\
Death & $6.6 \%(9), 11.5 \%(54)$ \\
Pnemonia & $11 \%(9)$ \\
Arrythmias & $17 \%(9), 5.7 \%(54)$ \\
Pacer/ICD & $9 \%(9)$ \\
Neurologic & $5 \%(9), 1.9 \%(54)$ \\
Renal Failure & $6 \%(9), 3.8 \%(54)$ \\
Prolongued intubation & $10 \%(9), 32.7 \%(54)$ \\
Sepsis & $1.9 \%(54)$ \\
Postoperative bleeding & $5.7 \%(54)$ \\
Low CO syndrome & $13.4 \%(54)$ \\
Cardiac tamponade & $1.9 \%(54)$ \\
\hline
\end{tabular}

${ }^{*}$ Mainly transapical access. ICD, internal cardiac desfibrillator; CO: cardiac output.

PVLs also are shown in Table 2. As reported by Akins, ${ }^{9}$ only $46 \%$ of patients were free of perioperative complications such as prolonged intubation, arrhythmia, pneumonia, re-exploration, renal failure, neurologic or gastro-intestinal events. Redo operative mortality was $6.6 \%{ }^{9}$

Consequently, the 2012 European Society of Cardiology (ESC) guidelines ${ }^{43}$ state that percutaneous PVL closure may be considered in patients at high risk of reoperation and the 2014 American Heart Association/American College of Cardiology (AHA/ACC) guidelines ${ }^{44}$ granted to this procedure a level of recommendation of IIa.

\section{Treatment and Follow-Up After Paravalvular Leak Closure}

There is limited data regarding the time to endothelization of devices following PVL closure. ${ }^{45}$ 
In our centre, we reintroduce oral anticoagulants if there have been no complications after the procedure. In patients who are not on oral anticoagulants, we administer aspirin (100 mg/day) and clopidogrel ( $75 \mathrm{mg} /$ day) for 3 months. In addition, all patients undergo a TTE 24 hours after the procedure to rule out complications. At 3 months after discharge, patients are reviewed in outpatient clinics and we performed a TEE to assess the degree of PVR.

\section{Conclusions and Future Directions}

Symptomatic PVR is an uncommon but serious complication associated with surgical valve replacement. Percutaneous PVL closure is a technically challenging procedure requiring complex catheter techniques and a large interventional armamentarium. The success of the procedure is higher in centres with extensive experience in this field. Newer imaging modalities, including 3D-TEE and CT with 3D/4D reconstruction, are important for pre-procedural planning and intra-procedural guidance. Serious complication rates are low at experienced centres, but prompt recognition and management of potential complications is critical. Probably, new advancements in the material and the future arrival of specific devices more appropriate to the anatomy of the defects, this procedure may ultimately prove to become the gold standard treatment in this setting.

\section{References}

1. Jindani A, Neville EM, Venn G, et al. Paraprosthetic leak: A complication of cardiac valve replacement. J Cardiovasc Surg (Torino) 1991;32:503-508.

2. Saia F, Martinez C, Gafoor S, et al. Long-term outcomes of percutaneous paravalvular regurgitation closure after transcatheter aortic valve replacement: A multicenter experience. JACC Cardiovasc Interv 2015;8:681-688.

3. Ionescu A, Fraser AG, Butchart EG. Prevalence and clinical significance of incidental paraprosthetic valvar regurgitation: A prospective study using transoesophageal echocardiography. Heart 2003;89:1316-1321.

4. De Cicco G, Russo C, Moreo A, et al. Mitral valve periprosthetic leakage: Anatomical observations in 135 patients from a multicentre study. Eur J Cardiothorac Surg 2006;30:887-891.

5. Sinning JM, Vasa-Nicotera M, Chin D, et al. Evaluation and management of paravalvular aortic regurgitation after transcatheter aortic valve replacement. J Am Coll Cardiol 2013;62: $11-20$.

6. Genoni M, Franzen D, Vogt P, et al. Paravalvular leakage after mitral valve replacement: Improved long-term survival with aggressive surgery? Eur J Cardiothorac Surg 2000;17: $14-19$.
7. Schaff HV, Carrel TP, Jamieson WR, et al. Paravalvular leak and other events in silzone-coated mechanical heart valves: A report from AVERT. Ann Thorac Surg 2002;73:785-792.

8. Echevarria JR, Bernal JM, Rabasa JM, et al. Reoperation for bioprosthetic valve dysfunction. A decade of clinical experience. Eur J Cardiothorac Surg 1991;5:523-526; discussion 527

9. Akins CW, Bitondo JM, Hilgenberg AD, et al. Early and late results of the surgical correction of cardiac prosthetic paravalvular leaks. J Heart Valve Dis 2005;14:792-799.

10. Ruiz CE, Jelnin V, Kronzon I, et al. Clinical outcomes in patients undergoing percutaneous closure of periprosthetic paravalvular leaks. J Am Coll Cardiol 2011;58:2210-2217.

11. Sorajja P, Cabalka AK, Hagler DJ, et al. Long-term follow-up of percutaneous repair of paravalvular prosthetic regurgitation. J Am Coll Cardiol 2011;58:2218-2224.

12. Sorajja P, Cabalka AK, Hagler DJ, et al. Percutaneous repair of paravalvular prosthetic regurgitation: Acute and 30-day outcomes in 115 patients. Circ Cardiovasc Interv 2011;4: 314-321.

13. Millan X, Skaf S, Joseph L, et al. Transcatheter reduction of paravalvular leaks: A systematic review and meta-analysis. Can J Cardiol 2015;31:260-269.

14. Lazaro C, Hinojar R, Zamorano JL. Cardiac imaging in prosthetic paravalvular leaks. Cardiovasc Diagn Ther 2014;4:307-313.

15. Zamorano JL, Badano LP, Bruce $\mathrm{C}$, et al. EAE/ASE recommendations for the use of echocardiography in new transcatheter interventions for valvular heart disease. Eur Heart J 2011;32:2189-2214.

16. Matsumoto M, Inoue M, Tamura S, et al. Three-dimensional echocardiography for spatial visualization and volume calculation of cardiac structures. J Clin Ultrasound 1981;9:157-165.

17. Singh P, Manda J, Hsiung MC, et al. Live/real time threedimensional transesophageal echocardiographic evaluation of mitral and aortic valve prosthetic paravalvular regurgitation. Echocardiography 2009;26:980-987.

18. Kronzon I, Sugeng L, Perk G, et al. Real-time 3-dimensional transesophageal echocardiography in the evaluation of postoperative mitral annuloplasty ring and prosthetic valve dehiscence. J Am Coll Cardiol 2009;53:1543-1547.

19. Garcia-Fernandez MA, Cortes M, Garcia-Robles JA, et al. Utility of real-time three-dimensional transesophageal echocardiography in evaluating the success of percutaneous transcatheter closure of mitral paravalvular leaks. J Am Soc Echocardiogr 2010;23:26-32.

20. Arribas-Jimenez A, Rama-Merchan JC, Barreiro-Perez M, et al. Utility of real-time 3-dimensional transesophageal echocardiography in the assessment of mitral paravalvular leak. Cir J 2016; Jan 26. (Epub ahead of print)

21. Faletra FF, Pedrazzini G, Pasotti E, et al. 3D TEE during catheter-based interventions. JACC Cardiovasc Imaging 2014;7:292-308.

22. Deftereos S, Giannopoulos G, Raisakis K, et al. Intracardiac echocardiography imaging of periprosthetic valvular regurgitation. Eur J Echocardiogr 2010;11:E20.

23. Hoffmann R, Kaestner W, Altiok E Closure of a paravalvular leak with real-time three-dimensional transesophageal echocardiography for accurate sizing and guiding. J Invasive Cardiol 2013;25:E210-E211.

24. Kumar R, Jelnin V, Kliger C, et al. Percutaneous paravalvular leak closure. Cardiol Clin 2013;31:431-440.

25. Biaggi P, Fernandez-Golfin C, et al. Hybrid imaging during transcatheter structural heart interventions. Curr Cardiovasc Imaging Rep 2015;8:33.

26. Yuksel UC, Tuzcu EM, Kapadia SR Percutaneous closure of a postero-medial mitral paravalvular leak: The triple telescopic system. Catheter Cardiovasc Interv 2011;77:281-285. 


\section{CRUZ-GONZALEZ, ET AL.}

27. Cruz-Gonzalez I, Rama-Merchan JC, Rodriguez-Collado J, et al. Percutaneous paravalvular leak closure in "Invisible" mitral valve bioprosthesis without radio-opaque indicators. Can J Cardiol 2015;31:1205.e7-1205.e8.

28. Cruz-Gonzalez I, Rama-Merchan JC, Martin-Moreiras J, et al. Percutaneous retrograde closure of mitral paravalvular leak in patients with mechanical aortic valve prostheses. Can J Cardiol 2013;29:1531.e15-1531.e16.

29. Cruz-Gonzalez I, Rodriguez-Collado J, Arribas-Jimenez A, et al. First-in-man percutaneous transseptal closure of paravalvular regurgitation after percutaneous valve-in-ring implantation. JACC Cardiovasc Interv 2015;8:e115-e116.

30. Damluji AA, Kaynak HE, Heldman AW Combined retrograde/ antegrade approach to transcatheter closure of an aortic paravalvular leak. Tex Heart Inst J 2015;42:443-447.

31. Webb JG, Pasupati S, Humphries K, et al. Percutaneous transarterial aortic valve replacement in selected high-risk patients with aortic stenosis. Circulation 2007;116:755-763.

32. De Jaegere PP, Piazza N, Galema TW, et al. Early echocardiographic evaluation following percutaneous implantation with the self-expanding CoreValve Revalving System aortic valve bioprosthesis. EuroIntervention 2008;4:351-357.

33. Rodes-Cabau J, Webb JG, Cheung A, et al. Transcatheter aortic valve implantation for the treatment of severe symptomatic aortic stenosis in patients at very high or prohibitive surgical risk: Acute and late outcomes of the multicenter Canadian experience. J Am Coll Cardiol 2010;55:1080-1090.

34. Athappan G, Patvardhan E, Tuzcu EM, et al. Incidence, predictors, and outcomes of aortic regurgitation after transcatheter aortic valve replacement: Meta-analysis and systematic review of literature. J Am Coll Cardiol 2013;61:1585-1595.

35. Genereux P, Head SJ, Hahn R, et al. Paravalvular leak after transcatheter aortic valve replacement: The new Achilles' heel? A comprehensive review of the literature. J Am Coll Cardiol 2013;61:1125-1136

36. Kodali SK, Williams MR, Smith CR, et al. Two-year outcomes after transcatheter or surgical aortic-valve replacement. N Engl J Med 2012;366:1686-1695.

37. Tamburino C, Capodanno D, Ramondo A, et al. Incidence and predictors of early and late mortality after transcatheter aortic valve implantation in 663 patients with severe aortic stenosis. Circulation 2011;123:299-308.

38. Cruz-Gonzalez I, Rama-Merchan JC, Arribas-Jimenez A, et al. Paravalvular leak closure with the Amplatzer Vascular Plug III device: Immediate and short-term results. Rev Esp Cardiol (Engl Ed) 2014;67:608-614.

39. Sanchez-Recalde A, Moreno R, Galeote G, et al. Immediate and mid-term clinical course after percutaneous closure of paravalvular leakage. Rev Esp Cardiol (Engl Ed) 2014;67:615-623.

40. Smolka G, Pysz P, Jasinski M, et al. Multiplug paravalvular leak closure using Amplatzer Vascular Plugs III: A prospective registry. Catheter Cardiovasc Interv 2015; May 11. (Epub ahead of print)

41. Goktekin O, Vatankulu MA, Tasal A, et al. Transcatheter transapical closure of paravalvular mitral and aortic leaks using a new device: First in man experience. Catheter Cardiovasc Interv 2014;83:308-314.

42. Noble S, Jolicoeur EM, Basmadjian A, et al. Percutaneous paravalvular leak reduction: Procedural and long-term clinical outcomes. Can J Cardiol 2013;29:1422-1428.

43. Vahanian A, Alfieri O, Andreotti F, et al. Guidelines on the management of valvular heart disease (version 2012). Eur Heart J 2012;33:2451-2496.

44. Nishimura RA, Otto CM, Bonow RO, et al. 2014 AHA/ACC guideline for the management of patients with valvular heart disease: Executive summary: A report of the American College of Cardiology/American Heart Association Task Force on Practice Guidelines. J Am Coll Cardiol 2014;63:2438-2488.

45. Ozkan M, Astarcioglu MA, Gursoy MO Evaluation of endothelialization after percutaneous closure of paravalvular leaks. J Invasive Cardiol 2012;24:E72-E74.

46. Hein R, Wunderlich N, Robertson G, et al. Catheter closure of paravalvular leak. EuroIntervention 2006;2:318-325.

47. Cortes M, Garcia E, Garcia-Fernandez MA, et al. Usefulness of transesophageal echocardiography in percutaneous transcatheter repairs of paravalvular mitral regurgitation. Am J Cardiol 2008;101:382-386.

48. García-Borbolla Fernández R, Sancho Jaldón M, Calle Pérez G, et al. Percutaneous treatment of mitral valve periprosthetic leakage. An alternative to high-risk surgery? Rev Esp Cardiol 2009;62:438-441.

49. Nietlispach F, Johnson M, Moss RR, et al. Transcatheter closure of paravalvular defects using a purpose-specific occluder. JACC Cardiovasc Interv 2010;3:759-765.

50. Swaans MJ, Post MC, van der Ven HA, et al. Transapical treatment of paravalvular leaks in patients with a logistic euroscore of more than 15\%: Acute and 3-month outcomes of a "proof of concept" study. Catheter Cardiovasc Interv 2012;79: 741-747.

51. Boccuzzi GG, De Rosa C, Scrocca I, et al. Percutaneous closure of periprosthetic paravalvular leak: Single center experience. J Clin Exp Cardiol 2013;S3:7.

52. Smolka G, Pysz P, Wojakowski W, et al. Clinical manifestations of heart failure abate with transcatheter aortic paravalvular leak closure using Amplatzer Vascular Plug II and III devices. J Invasive Cardiol 2013;25:226-231.

53. Smolka G, Pysz P, Jasinski M, et al. Transapical closure of mitral paravalvular leaks with use of amplatzer Vascular Plug III. J Invasive Cardiol 2013;25:497-501.

54. Choi JW, Hwang HY, Kim KH, et al. Long-term results of surgical correction for mitral paravalvular leak: Repair versus re-replacement. J Heart Valve Dis 2013;22:682-687. 
Copyright of Journal of Interventional Cardiology is the property of Wiley-Blackwell and its content may not be copied or emailed to multiple sites or posted to a listserv without the copyright holder's express written permission. However, users may print, download, or email articles for individual use. 